\title{
Moving Forward in Tackling the Double Burden of Malnutrition: The "International Symposium on Understanding the Double Burden of Malnutrition for Effective Interventions"
}

\author{
Cornelia U. Loechl $^{a}$ Francesco Branca $^{b}$ Victor Aguayo ${ }^{c}$ \\ a Division of Human Health, Department of Nuclear Sciences and Applications, International Atomic Energy Agency \\ (IAEA), Vienna International Centre, Vienna, Austria; ${ }^{\mathrm{b}}$ Department of Nutrition for Health and Development, World \\ Health Organization (WHO), Geneva, Switzerland; ' ${ }^{C}$ utrition Programme, Programme Division, United Nations \\ Children's Fund (UNICEF), New York, NY, USA
}

\section{Introduction}

Nutrition is an important factor that contributes to international health and development. Malnutrition is associated with mortality and poor health, growth and development, with negative impacts on social and economic development. Malnutrition, in all its forms, is the outcome of a suboptimal diet and/or physical inactivity and/or infections with 1 in 3 persons affected globally [1]. Despite reductions in stunting, recent estimates [2] indicate that 149 million children $<5$ years are stunted and 49 million are wasted. At the same time, overweight among children $<5$ years is increasing with 40 million children classified as overweight or obese [2]. In addition, 1 in 3 women of reproductive age has anaemia [1]. Low- and middle-income countries bear the biggest burden with Africa and Asia having the greatest share of all forms of malnutrition [2].

The double burden of malnutrition (DBM) has become the new norm. The DBM is defined as the coexistence of undernutrition along with overweight/obesity or diet-related non-communicable diseases (NCDs), within individuals, households and populations and across the life course [3]. No region or country is immune to the DBM. The Global Nutrition Report 2018 [4] indicates that $88 \%$ of the countries (124 of the 141 analysed) experience $>1$ form of malnutrition and $29 \%$ (41 countries) had high levels of childhood stunting, anaemia and overweight in adult women. This calls for immediate actions to support the achievement of the 2030 Sustainable Development Goals 2 and 3 [5] and the commitments of the Rome Declaration on Nutrition [6].

Epidemiological and nutrition transitions have accelerated due to economic and income growth, urbanization, and globalization resulting in shifts from undernutrition and infectious diseases to overweight/obesity and diet-related NCDs. Diet-related NCDs, that is, cardiovascular disease, cancer, chronic respiratory disease and diabetes, are responsible for $79 \%$ of global deaths each year (32 out of an estimated 41 million deaths occurring due to NCDs) [7], burdening mostly low- and middle-income countries and resulting in losses in economic growth and human capital [8].

The article is part of the Proceedings of the International Symposium on Understanding the Double Burden of Malnutrition for Effective Interventions organized by the International Atomic Energy Agency (IAEA) in cooperation with United Nations Children's Fund (UNICEF) and World Health Organization (WHO) (10-13 December 2018, Vienna, Austria).

\section{KARGER}

E-Mail karger@karger.com www.karger.com/anm

\section{- International Atomic Energy Agency 2019 Karger Published by S. Karger AG, Basel Open access} All rights reserved.

This is an Open Access article licensed under the terms of the Creative Commons Attribution 3.0 IGO License (CC BY 3.0 IGO)https://creativecommons.org/licenses/by/3.0/igo/\#). Usage, distribution and reproduction in any medium or format, even for commercial purposes, is permitted, provided the original work is properly cited.
Division of Human Health, Department of Nuclear Sciences and Applications International Atomic Energy Agency, Vienna International Centre PO Box 100, AT-1400 Vienna (Austria)

E-Mail C.U.Loechl@iaea.org 
Double-duty actions can be effective approaches in addressing the DBM and are defined as interventions, programmes and policies that can simultaneously reduce the risk or burden of both undernutrition and overweight, obesity or diet-related NCDs [9].

\section{Goals of the Symposium}

The United Nations Decade of Action on Nutrition 2016-2025 [10] calls upon Member States to undertake sustained and coherent actions. The Decade provides a unique opportunity for stakeholders to strengthen joint efforts towards eradicating hunger and preventing all forms of malnutrition worldwide. In support of the $\mathrm{Nu}$ trition Decade and in response to the rising DBM, the International Atomic Energy Agency (IAEA), the United Nations Children's Fund (UNICEF) and the World Health Organization (WHO) joined forces to organize an international symposium with the aim of strengthening collective actions across organizations, countries and communities to move forward the DBM agenda through a multi-agency approach. The International Symposium on "Understanding the Double Burden of Malnutrition for Effective Interventions" [11] took place in Vienna from 10 to 13 December 2018 and was preceded by a joint IAEA-UNICEF-WHO workshop in 2017 [12] on analysing biological pathways to better understand the DBM and to inform action planning. The symposium aimed to estimate and explore the global magnitude of the DBM, share evidence on biological pathways through which early nutrition influences NCDs, identify the role of stable isotope techniques and new tools in assessing the DBM, review the effectiveness of existing double-duty actions, review efforts that have been undertaken so far to create nutrition-enabling environments, recommend double-duty actions and discuss considerations for the design of contextually relevant policies.

Over 460 scientists, health and nutrition professionals and policy makers representing 91 countries and 21 organizations participated in the 4 -day symposium. The symposium was structured around 15 sessions covering the preconception period, the first 1,000 days, undernutrition, obesity and food systems [12]. The plenary sessions focused on bridging from biology and assessment to context relevant interventions and policies. After a presentation of the biological evidence, available indicators on exposure and outcomes were discussed, followed by sharing experiences on public health interventions and then presentations on policy applications and implications. The symposium served as a platform for participants to strengthen their understanding of how to tackle the DBM, share experiences with the implementation of relevant interventions, programmes and policies and learn about new assessment tools such as stable isotopes to measure malnutrition in all its forms and to assess the impact of interventions. The epidemiology and magnitude of the DBM in different regions, landscape of actions and programmatic experiences were highlighted and discussed in 4 parallel regional sessions reflecting WHO regional grouping [13]. The symposium also served as venue for the official launch of the first comprehensive database comprising measurements of total energy expenditure (TEE), the IAEA Doubly Labelled Water Database [14] and a launch of the Global Nutrition Report 2018 [3]. In addition, small working groups discussing specific topics and learning labs on new technology were organized.

\section{The Way Forward: Programmatic Implications and Strategic Orientations}

Three themes were identified as being critical to reduce the DBM: create enabling environments for healthy behaviours throughout the life course, focus on double duty and multi-sectoral actions and need for better data.

A positive enabling environment is important to contribute to good nutrition at each life stage, from before conception to old age. Nutrition is critical in children in the first years of life, adolescents and young adults. The nutrition of adolescent girls is particularly important because it is linked to the health and nutrition of future generations. Key considerations relate to the connection between undernutrition in early childhood and higher risk of obesity and NCDs later in life due to a low metabolic capacity of the body to deal with a variety of factors such as unhealthy diets and physical inactivity, amongst others. It is therefore important to create a supportive environment to promote appropriate infant and young child feeding practices and to enable women to breastfeed according to international recommendations. There is no "one size fits all" when it comes to intervention design and implementation. Adaptations and tailoring of interventions to local contexts are critical.

Better indicators for monitoring and evaluation of interventions, programmes and policies and the surveillance of population health and nutrition are needed to tackle the DBM. This will also help countries to track progress against national commitments. Key considerations include adequately measuring breastfeeding practices to provide better guidance for related policies and programmes and the need for objective data on body composition for the evaluation of interventions address-
Loechl/Branca/Aguayo 
ing healthy growth and overweight and obesity in all age groups. Body composition differentiates between lean and fat mass. Therefore, it provides information on more than one form of malnutrition and allows an accurate assessment of the DBM. It is also important to obtain data on the implementation process and the impact of interventions in programme evaluations to better inform programming and make programmes more effective.

Strong government commitment and multi-sectoral engagement were identified as being key to the effective response to the DBM. It was agreed that double-duty actions addressing more than one form of malnutrition are effective approaches to tackle the DBM. The need for actions that make the healthy choice an easy choice, create healthier food environments and encourage food systems to focus on children's diets was emphasized.

\section{Contents of the Proceedings}

The proceedings contain a series of papers that summarize the symposium discussions related to the key contribution of the preconception period and the first 1,000 days of life - from conception to 2 years - to prevent the DBM, accurate assessment of different aspects of the DBM to strengthen data systems, regional examples of programmes and policies, how to bridge from biology to implementation and further research gaps. The papers are authored by the symposium organizers, members of the symposium advisory committee and invited experts.

The supplement opens with a paper by Hoffman et al. emphasizing the importance of the preconception and pregnancy periods, breastfeeding and complementary feeding as key contributors to the DBM and how to effectively improve nutrition in infancy and early childhood. The next 3 papers by Wells, Slater et al. and Speakman et al. describe assessment techniques relevant to the context of the DBM. Wells describes a conceptual framework for integrating data on different components of body composition in order to predict NCD risk and the variety of techniques available for the measurement of body composition in the second paper. In the third paper, Slater et al. provide an overview of the objective method of assessing breastfeeding practices using stable isotope techniques, new developments and examples of use. The importance of data on TEE in the context of the DBM and the new IAEA database containing measures of TEE by doubly labelled water are presented by Speakman et al. in the fourth paper. Major outcomes of the working groups on integrating stable isotope techniquederived nutrition indicators in nutrition surveillance are presented by Owino et al. in the fifth paper, while Haisma et al. present the development and use of a multi-dimensional index for child growth and development in the sixth paper. The following 4 papers by Onyango et al., de Silva et al., Yarparvar et al. and Grajeda et al. capture region-specific discussions on several aspects of the DBM problem, possible solutions and the way forward for the different regions. Kraemer et al. describe the key role of translational and implementation research to improve the use of biological evidence and science in programmes in the eleventh paper. The proceedings end with a discussion on a research agenda to reverse global trends of the DBM by Hoffman.

We hope that the information and recommendations contained in the proceedings will contribute towards successful reduction of the DBM.

\section{Acknowledgements}

The authors thank the symposium advisory committee members and invited speakers for their valuable inputs on the symposium agenda and for excellent presentations during the symposium. The authors also thank Maaike Arts, Marzella Wustefeld, Theodora Mouratidou and Pernille Kaestel for reviewing this manuscript and their valuable suggestions.

\section{Disclosure Statement}

The authors have no conflicts of interest to declare in relationship to the content of the manuscript.

\section{Funding Sources}

The Swiss Federal Office of Energy provided partial funding to the open access publication of the proceedings.

Open access provided with a grant from the International Atomic Energy Agency.

\section{Author Contributions}

C.U.L. wrote the first draft of the manuscript; F.B. and V.A. critically revised it; all authors approved the manuscript.

\section{Disclaimer}

The statements, opinions and data contained in this publication are solely those of the individual authors and contributors, not of the publishers and the editor(s), and do not necessarily reflect the views of the cooperating organizations, IAEA, UNICEF and WHO. The use of particular designations of countries or territories 
does not imply any judgement by the cooperating organizations, as to the legal status of such countries or territories, of their authorities and institutions or of the delimitation of their boundaries. The mention of names of specific companies or products (wheth- er or not indicated as registered) does not imply any intention to infringe proprietary rights, nor should it be construed as an endorsement or recommendation on the part of the cooperating organizations.

\section{References}

1 FAO, IFAD, UNICEF, WFP and WHO. The State of Food Security and Nutrition in the World 2018. Building climate resilience for food security and nutrition. Rome: FAO; 2018.

2 United Nations Children's Fund (UNICEF), World Health Organization, International Bank for Reconstruction and Development/ The World Bank. Levels and trends in child malnutrition: key findings of the 2019 Edition of the Joint Child Malnutrition Estimates. Geneva: World Health Organization; 2019.

3 WHO. The double burden of malnutrition. Policy brief. Geneva: World Health Organization; 2017.

4 Development Initiatives. 2018 Global Nutrition Report: Shining a light to spur action on nutrition. Bristol: Development Initiatives; 2018.
5 United Nations. Sustainable Development Goals Knowledge Platform. Available from: https://sustainabledevelopment.un.org/.

6 FAO, WHO. Conference Outcome Document: Rome Declaration on Nutrition. Rome: Second International Conference on Nutrition; 2014.

7 World Health Organization. World health statistics 2018: monitoring health for the SDGs, sustainable development goals. Geneva; 2018.

8 Branca F, Lartey A, Oenema S, Aguayo V, Stordalen GA, Richardson R, et al. Transforming the food system to fight non-communicable diseases. BMJ. 2019;365:1296.

9 WHO. Double-duty actions. Policy Brief. Geneva: World Health Organization; 2017.

10 United Nations. United Nations Decade of Action on Nutrition 2016-2025. Available from: https://www.un.org/nutrition/.
11 International Atomic Energy Agency. International Symposium on Understanding the Double Burden of Malnutrition for Effective Interventions. Vienna, Austria 2018. Available from: https://www.iaea.org/events/ understanding-the-double-burden-ofmalnutrition-symposium-2018.

12 International Atomic Energy Agency. DBMal Symposium 2018. Available from: http:// humanhealth.iaea.org/HHW/Nutrition/ Symposium2018/index.html

13 World Health Organization. WHO regional offices. Available from: https://www.who.int/ about/who-we-are/regional-offices.

14 International Atomic Energy Agency. New IAEA Database to Help Countries Tackle Growing Obesity Crisis. Vienna, Austria 2018. Available from: https://www.iaea.org/ newscenter/pressreleases/new-iaea-databaseto-help-countries-tackle-growing-obesitycrisis. 